21

\title{
Treatment of colonoscopic perforation - outcomes from a major single tertiary institution
}

\section{Carolyn R Chew MBBS, BMedSci ${ }^{1}$, Justin MC Yeung BMedSci, BMBS, FRCSEd (Gen Surg), DM, DipMedEd ${ }^{1,2}$, Ian G Faragher, FRACS, FCSSANZ ${ }^{1,2}$}

1. Department of Colorectal Surgery, Footscray Hospital, Western Health, 160 Gordon Street, Footscray

Victoria, 3011 Australia

2. Department of Surgery

Level 3, WCHRE, Sunshine Hospital, Western Health, 176 Furlong Road, St Albans, Victoria 3021, Australia

Short title: Outcomes Colonoscopic Perforation

Correspondence to: Dr Carolyn Chew

Department of Surgery, Level 1,

Footscray Hospital

Western Health, Gordon St, Footscray 3011 Victoria

Ph. +61383456666

Fax. +61383456885

Carolyn.r.chew@icloud.com

Disclosures: No interests to declare. No funding support was received.

Presentations: Podium presentation at Royal Australian College of Surgeons Annual Scientific Congress, Brisbane, Australia, 2-9 May 2016.

Manuscript Word Count: 2964 (excluding abstract, acknowledgments, figure legends and references)

\author{
Abstract Word Count: 225
}

Number of Figures: 1

Number of Tables: 1

This is the author manuscript accepted for publication and has undergone full peer review but has not been through the copyediting, typesetting, pagination and proofreading process, which may lead to differences between this version and the Version of Record. Please cite this article as doi: 10.1111/ans.15068

This article is protected by copyright. All rights reserved. 


\begin{abstract}
Background

The use of colonoscopy has been increasing in Australia. This case series describes management and outcomes of colonoscopic perforation managed by a single tertiary referral unit.
\end{abstract}

Methods

An analysis of 13 years (2003 - 2015) of prospectively collected data on patients who had a colonoscopic perforation and were managed by the colorectal unit at a single tertiary referral centre was performed. Main outcomes were time of diagnosis, modality of management, time to theatre, length of stay, cost of admission and complications.

Results

Sixty-two patients had perforations (median age of 69$)$. Thirty-eight patients $(61.2 \%)$ had their colonoscopy performed in another institution. The incidence rate decreased to 0.37 perforations per 1000 colonoscopies within WH. Overall, diagnostic colonoscopies accounted for $56 \%$ of perforations and perforations were likely to occur in the left colon $(\mathrm{p}=0.006)$. Fifty-one patients (82\%) underwent surgery during their admission, with $24 \%$ of these being laparoscopic procedures. 
An earlier diagnosis was associated with significantly less intra abdominal contamination. Gross peritoneal contamination was more likely to be associated with the decision to form a stoma $(37 \%, n=19, p=0.04)$. Thirty-day mortality was $1.6 \%(n=1)$.

\section{Conclusions}

Colonoscopic perforations occur in experienced hands and may have serious implications. We demonstrated a difference in patterns of injury between therapeutic and diagnostic colonoscopies. Those who have an earlier diagnosis are less likely to have severe intra abdominal contamination requiring a stoma formation. 


\section{INTRODUCTION}

The use of colonoscopy is increasing in Australia, as the primary modality diagnosis of colonic pathology, treatment of polyps and surveillance of patients with colorectal neoplasia. Although iatrogenic perforation is a rare complication of colonoscopy, with rates between $0.03 \%-0.8 \%$ for diagnostic colonoscopy and $0.15-3 \%$ for therapeutic colonoscopy, ${ }^{1}$ those who develop this complication are associated with a significant morbidity and mortality. ${ }^{2}$

As colonoscopic perforation remains a rare event, there are no specific guidelines within Australia or the United Kingdom for the management of these patients. ${ }^{3-6}$ Data on perforation management and outcomes remains scarce and is largely based on retrospective case series. Within Australia, a significant proportion of colonoscopies are performed in the private sector. In the period of $2008-2009,75 \%$ of all colonoscopies were performed privately. ${ }^{7}$ Within our region, complications are usually managed within the public system. Traditionally, management consists of prompt transfer to theatre for laparotomy. Recently patient treatment has evolved with nonoperative management, endoscopic clipping and laparoscopy emerging as treatment options.

Our unit began to document colonoscopic perforation in 2003. This study is a thirteen-year review of these prospectively recorded cases managed by a single tertiary. We aim to describe incidence, practice, associations and outcomes after colonoscopic perforation.

\section{MATERIALS AND METHODS}

This article is protected by copyright. All rights reserved. 
Prospective data were collected for all patients with a colonoscopic perforation managed by the Colorectal Unit at Western Health, Victoria, Australia between 2003 and 2015 inclusive. Patient demographics, indication for endoscopy, type of endoscopic procedure, diagnostic modality and site of perforation were recorded. Treatment outcomes including time course, surgical intervention, degree of contamination at time of surgery, stoma rate, length of stay, morbidity, mortality and cost of admission were collected.

Contamination was defined as gross peritoneal soiling (from operation reports and coding item numbers). Perforation was defined as free gas on imaging for symptoms that developed on the day of colonoscopy. Diagnostic colonoscopy was defined as colonoscopy in which no polypectomy was performed. Therapeutic colonoscopy was defined as colonoscopy in which polypectomy was performed. The left colon was defined as distal to the splenic flexure. Time to diagnosis was calculated from scope time to the time of review and diagnosis made by medical staff or diagnosis on radiology. Time to surgery was calculated from scope time to operation start time. Hospital payments were calculated using the WIES (Weighted Inlier Equivalent Separation) from the patient's admission and the corresponding WIES value for that financial year to give an estimated charge for the admission.

\section{Statistical Analysis}

This article is protected by copyright. All rights reserved. 
Categorical variables were compared by using Fisher exact test or the chi-square test. Numerical variables were compared by using Student t-test or the Mann-Whitney test. Probability values $<0.05$ were accepted as statistically significant. Analyses were performed using SPSS (IBM Co, Armonk, NY, USA). The study was approved by the Western Health Ethics committee, Level 3 WCHRE, Sunshine Hospital.

\section{RESULTS}

Sixty two patients were included in this study; (26 males, 36 females) with a median age of 69 years. Thirty eight patients had their colonoscopy performed by a private provider (61.2\%) and were subsequently managed at our institution. Eighty-five percent $(n=53)$ of the perforations occurred with a consultant endoscopist, 3\% occurred with fellows and $11 \%$ occurred with trainees as the primary endoscopist.

Twenty four patients had a perforation from colonoscopy at $\mathrm{WH}$, an overall incidence of 0.91 per 1000 scopes. There was a decrease of $78 \%$ in the relative risk of colonoscopic perforation at WH in the second half of the study period (95\% CI: 44\%, 92\%). The incidence of colonoscopic perforation at WH during the second half of the study was 0.37 per 1000 colonoscopies.

Therapeutic colonoscopy accounted for $44 \%$ of perforations $(n=27)$. The site of perforation and mechanism of injury are summarised in Fig 1. Perforation after diagnostic colonoscopy was 
more likely to occur in the left colon. $(\mathrm{p}=0.0006)$. The diagnosis of the perforation was made by the endoscopist in $50 \%(n=31)$ of cases, emergency department staff in $24.2 \%$ of cases and colorectal unit staff in the remainder. The time to diagnosis ranged between 0 to 417 hours, with a median time of 5 hours. Therapeutic colonoscopies were associated with a longer time to diagnosis, with a mean time to diagnosis of 31.8 hours compared with diagnostic colonoscopy of 11.04 hours $(\mathrm{p}=0.002)$.

Patients were managed based on their clinical status at the discretion of the managing consultant. Only two patients in this series were treated with endoscopic clipping by the initial endoscopist.

Patients within our institution with no evidence of generalised peritonitis and no signs of severe sepsis $^{8}$ were treated conservatively. Conservative management consisted of hospital admission, bowel rest, intravenous fluids and antibiotics, analgesia as well as regular clinical assessment. Eleven patients $(18 \%)$ were successfully treated with conservative management. Those patients who failed conservative management (ie progression to generalised peritonitis or development of severe sepsis) then proceeded to surgical therapy. The remaining 51 patients $(82 \%)$ underwent surgery during their admission, including two patients who failed a trial of conservative management.

In patients who underwent surgery, the median time from diagnosis to surgery was 11.4 hours (range 0-262 hours). The operative management and treatment outcomes are outlined in Table 1. 
Extent of peritoneal contamination was recorded in the operative notes in $92 \%$ of cases $(n=47)$, of which 18 patients had "gross" intra-abdominal contamination.

Laparoscopy was utilised in $24 \%$ of patients $(n=12)$. Laparoscopic procedures included primary repair $(n=6)$, and laparoscopic anterior resection $(n=2)$. Laparoscopy was also utilised for localization of the perforation and colonic mobilisation prior to open repair $(n=4)$. Open procedures consisted of either a primary repair $(n=10)$, segmental resection $(n=4)$, right hemicolectomy $(n=8)$, anterior resection $(n=6)$, subtotal colectomy $(n=1)$ or a Hartmann's procedure $(n=14)$. One patient had a perforation in redundant colon between the fascia and a preexisting end colostomy (within the subcutaneous space) and thus underwent resection of the redundant colon and stoma revision.

Later diagnosis (as defined as $>24$ hours) was associated with greater intra abdominal contamination at time of operation $(n=14, p=0.005)$. Gross peritoneal contamination was identified at operation in $25 \%$ of patients and was associated with a stoma $(n=18, p=0.005)$. The incidence of new stoma formation was $37 \%(n=19)$.

The median length of stay (LOS) was nine days (range 1-94 days). There was one 30-day mortality $(1.6 \%)$ in an 89 year old female who underwent a Hartmann's procedure for a large sigmoid defect following colonoscopy at an external provider. She passed away secondary to 
respiratory failure after an extended intensive care admission. Major morbidity, as defined as Grade 3 (Clavien Dindo Classification) complication or above, occurred in $21 \%$ of patients $(n=13)$. These included pulmonary complications $(n=4)$, cardiovascular complications $(n=5)$, readmission for ileus $(n=1)$ and wound infection $(n=2)$. Two patients returned to theatre; one patient for an anastomotic leak following an anterior resection which was subsequently revised to a Hartmann's procedure, and one negative laparotomy for a suspected anastomotic leak on imaging. Costs to patients and the community were significant. The average charge for initial admission was \$AUD13,435 (range \$AUD500-\$129,666).

Formation of a stoma was associated with significant subsequent morbidity to patients. Of the 19 patients with stoma, fourteen patients went on to have readmission for reversal of stoma. In those undergoing reversal, median length of time with a stoma was 224.5 days (range 82 - 565 days). There were no mortalities upon readmission for reversal of stoma. Significant morbidity (grade 3 complications) occurred in $36 \%$ of patients $(n=5)$. The average hospital charge for closure of stoma was \$AUD11,957 (range \$AUD4077 - \$21509), with median LOS of 12 days.

\section{DISCUSSION}

Iatrogenic perforation remains a rare but serious complication of colonoscopy. It is associated with significant financial and non-financial costs to the patient and the community. Reported rates in the literature of perforation are between $0.03 \%-0.8 \%$ for diagnostic colonoscopy and a

This article is protected by copyright. All rights reserved. 
slightly higher incidence of $0.15-3 \%$ for therapeutic colonoscopy. ${ }^{9}$ However, it is possible that the true incidence is greater than quoted as these estimates rely on accurate diagnosis and capture of events. Smaller, subclinical perforations may not be diagnosed and can heal spontaneously. ${ }^{10}$

This study evaluated colonoscopic perforation management and outcomes managed by a single major tertiary unit in Australia over a 13 year period. Over this period there were a number of advancements with colonoscopy, including larger polypectomies being performed, endoscopic clips, high definition scopes and use of carbon dioxide insufflation. There was also a shift towards cold snare polypectomy, prophylactic clipping and increased utilization of laparoscopic surgery. In addition, improved training through colonoscopy courses run by the Gastroenterological Society of Australia (GESA), ${ }^{5}$ better access to training lists and mentorship to trainees may have had a positive impact on quality of endoscopy. The British Society of Gastroenterology found that there has been an improvement in quality of endoscopy over the years, however, regional variations still exist. ${ }^{3}$ The majority of cases $(61.2 \%)$ came from external endoscopy providers which is not surprising as we know that the majority of colonoscopies are performed in the private sector in Australia. ${ }^{7}$ Stand alone endoscopy services rarely perform removal of large polyps and do not manage their own complications. As the number of total procedures performed in our catchment is not known, a perforation rate for the entire cohort cannot be calculated. During the study, the perforation rate at our institution reduced to 0.37 per 1000 colonoscopies, below the target set by the U.S. Multi-Society Task Force on Colorectal 
Cancer of $\mathrm{d} 1$ per 1000 colonoscopies.${ }^{11}$ This is also in keeping with the ranges reported in caseseries for high-volume centres of $0.01-0.6 \% .^{12}$

Five distinct mechanisms of colonoscopic perforation have been identified in the literature. These include injury to the bowel by: by the tip of the colonoscope, bowing of a loop of the scope, perforation along a pathological area of the colon, barotrauma, and by polypectomy or thermal injury. ${ }^{10,12-15}$

Only in 21 of the total 62 patients was the perforation recognized at the time of the procedure. The remainder of cases required radiological imaging to confirm the perforation. Within our series, we demonstrated that there was a considerable difference to average time to diagnosis; 11.04 hours for diagnostic procedures compared with an average of 31.8 hours for therapeutic procedures. This difference may reflect different mechanisms of injury, and is comparable to previously described diagnosis times. ${ }^{3}$ We also demonstrated a difference in patterns of injury between therapeutic and diagnostic procedures, with the perforation location following diagnostic colonoscopy to more likely occur in the left colon. This may be due to negotiation of the sigmoid colon, adhesions or looping.

The difficulties in management of perforations are due to the large number of variables which influence the decision making, as well as the lack of clear evidence based guidelines. ${ }^{3-6}$ Location 
of perforation, underlying disease process, bowel preparation, patient's clinical status and comorbidities, radiological investigations and timing of diagnosis all need to be considered when managing these patients. ${ }^{12}$ Traditionally, management has comprised of prompt laparotomy, colonic repair or resection and peritoneal lavage. However, in recent years approach to treatment has shifted with the emerging role of conservative management and utilization of laparoscopy and endoscopic clipping. ${ }^{16}$

Endoscopic clipping is emerging as a management option for stable patients where the perforation is noted at the time of procedure. Endoscopic clipping (through the scope and over the scope techniques) have been shown to be effective in perforations $<2 \mathrm{~cm}$, with reported technical success rates of $93 \%$ and clinical success rates of $89 \% .{ }^{14}$ Our study only included two patients that were managed with endoscopic clipping, however we did not capture patients that were clipped endoscopically but were not referred to our colorectal service, thus we are unable to comment on the success rate at our facility.

Non-operative management has become an appropriate management strategy in a select group of patients. ${ }^{14,17-19}$ These patients require serial review and constant re-evaluation to identify signs of clinical deterioration and need for surgical intervention. The presence of pneumoperitoneum alone does not necessarily warrant surgical intervention. ${ }^{12,21}$ In a study of 22 patients by Won et al, abdominal pain and fever were shown to be the most important factors in deciding between 
conservative management and surgical intervention. ${ }^{20}$ In our series, thirteen patients were managed conservatively, with only two proceeding to surgery. When successful, conservative management has been shown to lead to less intervention and faster recovery. ${ }^{21,22}$

Operative management is determined by the intra-operative findings. Factors to consider include size and location of perforation, quality of the bowel preparation and extent of contamination as well as compromise to the mesentery. ${ }^{26}$ Review of previous studies reveal between $50-100 \%$ of patients with colonoscopic perforation undergo urgent laparotomy, with estimated morbidity rates of $34 \%$ and mortality rates of $25 \%{ }^{12,23-25}$

In select patients, laparoscopy is a useful tool and offers the advantages of being able to localise the perforation and secure the repair laparoscopically or through a smaller laparotomy incision. In this series, laparoscopy was utilised in $23.5 \%$ of those patients undergoing surgery. ${ }^{10}$ In a recent meta analysis, laparoscopic approaches resulted in better outcomes in terms of postoperative complications and length of stay in hospital. ${ }^{27}$

We tend to favour primary repair or resection with primary anastomosis, however if there is a significant degree of contamination or concern regarding patient clinical status, then an open resection with stoma is performed. Our series identified that an earlier diagnosis ( $<24$ hours) was associated with less intra-abdominal contamination. These findings are similar to previous 
studies, with Iqbal et al identifying patients presenting at $>24$ hours were more likely to have gross contamination and require faecal diversion. ${ }^{21}$ Time to diagnosis thus influences the operative management, as well as hospital length of stay. ${ }^{28}$

Currently the majority of patients requiring faecal diversion or colectomy do so via an open procedure. In our study, gross intra-peritoneal contamination was associated with a stoma, with an overall ostomy rate of $37 \%$, which is similar to other series in the literature of between $33.3 \%$ $-38.5 \%{ }^{29,30}$ Teoh et al agreed that peritoneal contamination and malignancy were the biggest predictors for stoma formation, with but reported no significant association with time to presentation, quality of bowel prep or age. ${ }^{30}$

Morbidity and mortality rates following iatrogenic perforation are significant. A systematic review by Hawkins et al of data from the last 10 years reported morbidity rates of $14-58 \%$ and mortality rates of up $26 \% .{ }^{31}$ Older age and larger perforation size have been demonstrated as independent mortality risk factors in patients with iatrogenic perforation. ${ }^{29,32}$ We report a similar morbidity rate $(21 \%)$ but a lower mortality rate $(1.6 \%)$. Our median length of hospital stay was 9 days.

There is limited published data looking at costs associated with colonoscopic perforation. Shin et al identified no significant difference in cost following laparotomy vs. laparoscopic 
management. ${ }^{33}$ In our series, the average charge of initial admission was AUD\$13,435, with charges for re-admission and reversal of stoma AUD $\$ 11,957$. This impact is often not reported. Given $61 \%$ of patients were from the private sector, this represents a significant transfer of costs from private to the public sector.

There are a number of limitations to our study. Not all patients who had colonoscopic perforations at our institution may have been captured in the study, particularly patients may have presented to other hospitals or patients who were managed endoscopically or conservatively by other units. However, we captured all patient data prospectively. As a majority of patients came from external providers, the surveillance interval was unknown. We do not have accurate information on the total number of scopes performed by individuals to calculate rates (incidences) for individuals. This was particularly difficult as referrals from private institutitions may be from a varying number of consultants. In future studies, it would be interesting to have a breakdown of logbook numbers/experience of individual endoscopists to compare outcomes between based on level of experienced and training (i.e. trainees vs. consultants). Not all factors pertinent to the perforation, such as the quality of the bowel preparation, duration of endoscopy and size of the polypectomy were documented in reports from private providers, and thus were unable to be analysed. The association between quality of bowel prep and intra abdominal contamination should be investigated. However, given colonoscopic perforation is such a rare event, we believe our relatively large number of cases in our series compared with the literature provides contemporaneous information regarding patterns of perforation and clinical outcomes. 
Our management principles are outlined below. If the perforation is recognised at time of colonoscopy, clipping of the defect should be considered. If the defect is large, or the patient is haemodynamically unstable with generalised peritonism they should proceed straight to theatre. Otherwise they should proceed to CT. Patients with small perforations who are clinically stable may be managed expectantly with intravenous antibiotics and serial clinical review, including patients who have been managed with endoscopic clipping. If they show any signs of deterioration, then prompt transfer to theatre is essential. This urgency is reflected in the recently published National Emergency Laparotomy Audit report which recommends patients access theatre within 2 hours. $^{34}$

Laparoscopy is useful for the initial assessment. Intra-operative decision making relies on the technical expertise of the surgeon, as well as individual patient factors such as age, comorbidities, clinical status, intra-abdominal contamination and size and site of perforation. Laparoscopic repair may be possible if the resources are available.

Iatrogenic perforation remains a rare but serious complication following colonoscopy. Two thirds of patients had their colonoscopy at an external provider, and $85 \%$ of cases were performed by consultant. The public sector manages many complications for the private sector. We observed a decrease in the perforation rate at our own institution during the study. In this series, perforation following diagnostic colonoscopy is more likely to occur in the left colon. 
Laparoscopic surgery may localise the perforation and allow repair. Delay to diagnosis is associated with greater intrabdominal contamination, and severe contamination is associated with higher likelihood of a stoma.

Colonoscopic perforation results in significant burden to patients, hospital and the wider community. 
1. Luning TH, Keemers-Gels ME, Bardendregt WB et al. Colonoscopic perforations: a review of 30,366 patients. Surg Endosc. 2007; 21: 994-997.

2. Perforation following colorectal endoscopy: what happens beyond the endoscopy suite? Tam MS, Abbas MA. Perm J. 2013; 17(2):17-21.

3. British Society of Gastroenterology. Clinical Guidelines. London, United Kingdom. [Updated 2018; cited 20 February 2018] Available from: https://www.bsg.org.uk/clinical/bsg-guidelines.html

4. The Association of Coloproctology of Great Britain and Ireland. Resources. London, United Kingdom. [Updated 2018; cited 20 February 2018]. Available from: https://www.acpgbi.org.uk/resources/

5. Gastroenterological Society of Australia. Clinical Guidelines. Melbourne, Australia. [Updated 2018; cited 20 February 2018]. Available from: http://www.gesa.org.au/resources/clinical-guidelines-and-updates/

6. Royal Australian College of Surgeons.Position Papers, Guidelines and Reports. Melbourne, Australia. [Updated 2018; cited 20 February 2018]. Available from:

https://www.surgeons.org/policies-publications/publications/position-papers/

7. Australian Government Department of Health and Ageing. Review of MBS colonoscopy items.[PDF on internet]. Canberra, Australia. [Updated 20 July 2011; cited 20 February 2018]. Available from: http://www.health.gov.au/internet/main/publishing.nsf/Content/Colonoscopy_Review.

This article is protected by copyright. All rights reserved. 
8. Australian Sepsis Network. Treatment of Sepsis [Online]. Newtown, Australia. [Update 2018; cited 28 October 2018]. Available from:

https://www.australiansepsisnetwork.net.au/healthcare-providers/treatment-sepsis

9. Wullstein Ch, Koppen MO, Gross E. Laparoscopic treatment of colonoscopic perforations related to colonscope. Surg Endosc. 1999; 13:484-487.

10. Luning TH, Keemers-Gels ME, Bardendregt WB et al. Colonoscopic perforations: a review of 30,366 patients .Surg Endosc. 2007; 21: 994-99).

11. Rex DK, Bond JH, Winawer S et al. Quality in the technical performance of colonoscopy and the continuous quality improvement process for colonoscopy: recommendations of the U.S. Multi-Society Task Force on Colorectal Cancer. Am J Gastroenterology. 2002; 97:1296-1308.

12. Avgerinos D, Llaguna O, Lo A, Leitman I. Evolving Management of Colonoscopic Perforations. J Gastrointest Surg. 2008; 12: 1783-1789.)

13. Kavic SM, Basson Md. Complications of endoscopy. Am J Surg. 2001; 181:319-332.

14. Araghizadeh FY, Timmcke AE, Opelka FG, Hicks TC, Beck DE. Colonoscopic perforations. Dis Colon Rectum. 2001; 44: 713-816

15. Dafnis G, Ekbom A, Pahlman L, Blomqvist P. Complications of diagnostic and therapeutic colonoscopy within a defined population in Sweden. Gastrintest Endosc. 2001; 54: 302-309.

This article is protected by copyright. All rights reserved. 
16. Management of iatrogenic colorectal perforation: From surgery to endoscopy. Cai SL, Chen T, Yao LQ, Zhong YS. World J Gastrointest Endosc. 2015; 7(8):819-23. doi: 10.4253/wjge.v7.i8.819. Review.

17. Christie JP, Marazzo J. "Mini-perforation" of the colon - not all postpolypectomy perforations require laparotomy. Dis Colon Rectum. 1991; 34:132-5.

18. Nivatvongs s. Complications in colonoscopic polypectomy: lessons to learn from an experience of 1576 polyps. Am Surg. 1988; 54:61-63

19. Carpio G, Albu E, Gumbs MA, Gerst PH. Management of colonic perforation after colonoscopy: report of three cases. Dis Colon Rectum. 1989; 32:624-6.

20. Won DY, Lee IK, Lee YS, Cheung DY. Choi SB, Jung H, Oh ST (2012). The indications for non-surgical management in patients with colorectal perforation after colonoscopy. The American Surgeon. 2012; 78: 550-554

21. Iqbal Cw, Shin Chun Y, Farley Dr. Colonsocopic perforations: a retrospective review. $J$ Gastrointest Surg. 2005; 9: 1229-1236.

22. An SB, Shin DW, Kim JY, Park SG, Lee BW, Kim JW. Decision-making in the management of colonoscopic perforation: a multicenter restrospective study. Surg Endosc. 2016; 30:2914-2921

23. Farley DR, Bannon MP, Zietlow SP, Pemberton JH, Ilstrup DM, Larson DR Management of perforation of the colon at colonoscopy. Am J Gastroenterol. 1992; 87: $161-167$

This article is protected by copyright. All rights reserved. 
24. Lo AY, Beaton HL. Selective management of colonoscopic perforations. J Am Coll Surg. 1994; 179:333-337.

25. Jentschura D, Raute M, Winter J, Henkel T, Kraus M, Manegold BC. Complications in endoscopy of the lower gastrointestinal tract. Surg Endosc. 1994; 8:672-676.

26. Makarawo T, Damadi A, Mittal V, Itawi E, Rana G. Colonoscopic perforation management by laparoendoscopy: an algorithm. JSLS. 2014; 18; 20-27.

27. Martínez-Pérez A, de'Angelis N, Brunetti F et al. Laparoscopic vs. open surgery for the treatment of iatrogenic colonoscopic perforations: a systematic review and metaanalysis. World J Emerg Surg. 2017;12:8.

28. Kim H, Kye B, Kim H, Cho H. Prompt management is most important for colonic perforation after colonoscopy. Ann Coloproctol. 2014; 30 (5): 228-231.

29. Farley, D, Bannon M, Ziftlow S, Pemberton J, Isltrup D, Larson D. Management of Colonoscopic perforations. Mayo Clin Proc. 1997;72( 8) 729-733

30. Teoh A et al. 2009 Outcomes and predictors of mortality and stoma formation in surgical management of colonoscopic perforations. Arch Surg 2009; 144 (1); 9-13.

31. Hawkins T et al. 2018. Management of colonoscopic perforations: a Systematic review. AJS 2018; 215; 712-718.

32. Yamamoto $\mathrm{T}$ et al. Prediction of mortality in patients with colorectal perforation based on routinely available parameters: a retrospective study. WJES. 2015;10:24. DOI 10.1186/s13017-015-0020-y

This article is protected by copyright. All rights reserved. 
33. Shin D, Shin S, Park C, Jin S, Cho Y, Kim W et al. Optimal methods for the management of Iatrogenic Colonoscopic perforation. Clin Endosc. 2016; 49 282-288

34. NELA Project Team, Royal College of Anaesthetists. Third Patient Report of the National Emergency Laparotomy Audit.[PDF on Internet]. London, United Kingdom. Updated October 2017; cited 01 July 2018. Available from:

https://www.nela.org.uk/reports

This article is protected by copyright. All rights reserved. 
Table 1: Clinical Outcomes according to treatment modality

\begin{tabular}{|c|c|c|c|c|}
\hline & Total (\%) & $\begin{array}{c}\text { Non-Operative } \\
\text { Treatment } \\
(n=11)\end{array}$ & $\begin{array}{c}\text { Surgical } \\
\text { Management } \\
(\mathrm{n}=51) \\
\end{array}$ & $\mathbf{p}$ \\
\hline Indication for scope & & & & 0.17 \\
\hline Therapeutic scopes & $\mathrm{n}=27$ & 7 & 20 & \\
\hline Diagnostic Scopes & $\mathrm{n}=35$ & 4 & 31 & \\
\hline Time to diagnosis, $h r$ & & 19.95 & 20.11 & 0.50 \\
\hline Diagnosis at endoscopy & & 1 & 24 & 0.04 \\
\hline Time interval to diagnosis & & & & 0.43 \\
\hline$<24$ hours & & 7 & 40 & \\
\hline Greater than 24 hours & & 4 & 11 & \\
\hline $\begin{array}{l}\text { Time diagnosis to theatre, } \\
h r \\
\text { Treatment }\end{array}$ & & - & 11.45 & \\
\hline Conservative treatment & & 10 & $1^{*}$ & \\
\hline Clipping & & 1 & $1^{*}$ & \\
\hline Primary closure & & - & 16 & \\
\hline $\begin{array}{r}\text { Bowel resection with } \\
\text { anastomosis }\end{array}$ & & - & 20 & \\
\hline Only faecal diversion & & - & 15 & \\
\hline Stoma, $n(\%)$ & & - & 19 & \\
\hline Major morbidity, $n(\%)$ & & $0(0)$ & 14 & 0.02 \\
\hline Mortality, $n$ & & $0(0)$ & 1 & 0.06 \\
\hline Length of stay (days) & & 5.6 & 15.3 & 0.04 \\
\hline Charge for admission $(\$)$ & & 3939.72 & $14,778.93$ & 0.28 \\
\hline
\end{tabular}

* These two patients are counted twice as they failed conservative treatment then subsequently proceeded to theatre

This article is protected by copyright. All rights reserved. 
Figure 1. Site of Perforation - Diagnostic vs Therapeutic scopes

Therapeutic Scopes: Site of Perforation, $n=27$ (44\%)

Diagnostic Scopes: Site of Perforation, $n=35$ (56\%)

This article is protected by copyright. All rights reserved. 


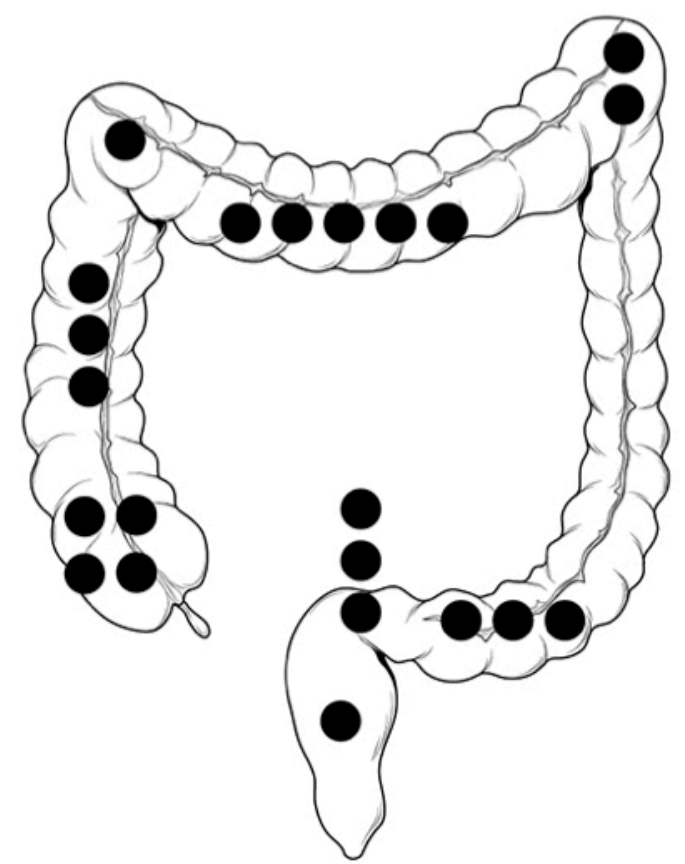

Therapeutic scopes

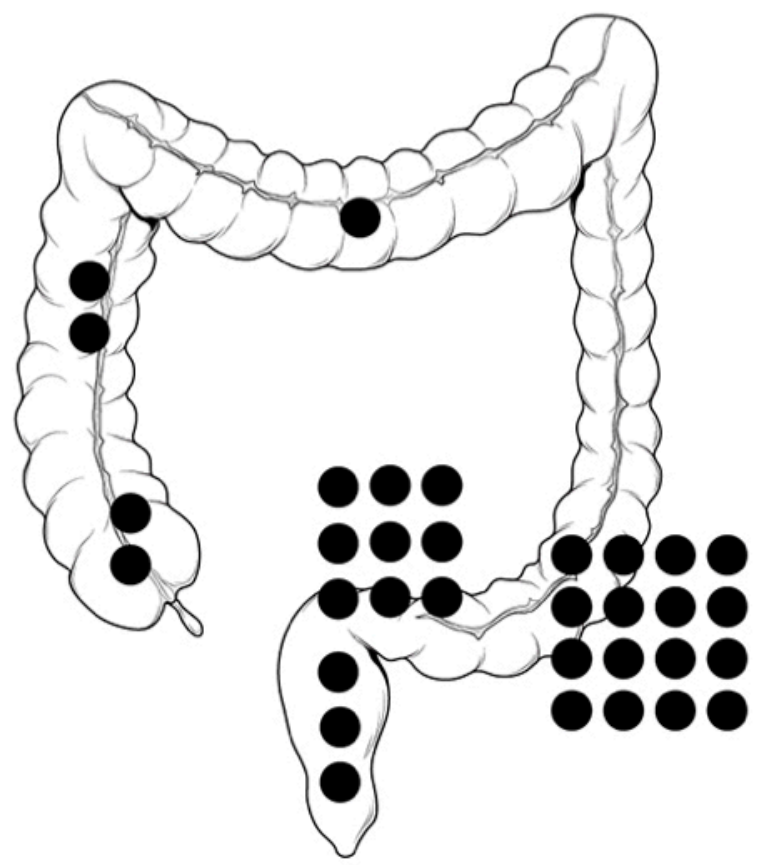

Diagnostic scopes

ANS_15068_PerforationsFig1.tiff

This article is protected by copyright. All rights reserved. 


\section{University Library}

\section{- M M I N E R VA A gateway to Melbourne's research publications}

Minerva Access is the Institutional Repository of The University of Melbourne

Author/s:

Chew, CR;Yeung, JMC;Faragher, IG

Title:

Treatment of colonoscopic perforation: outcomes from a major single tertiary institution

Date:

2019-05-01

Citation:

Chew, C. R., Yeung, J. M. C. \& Faragher, I. G. (2019). Treatment of colonoscopic perforation: outcomes from a major single tertiary institution. ANZ JOURNAL OF SURGERY, 89 (5), pp.546-551. https://doi.org/10.1111/ans.15068.

Persistent Link:

http://hdl.handle.net/11343/285636 